\title{
Effects of Ananas comosus leaf powder on broiler performance, haematology, biochemistry, and gut microbial population
}

\author{
Md. Mahbubur Rahman ${ }^{1,3}$, Dong Kwon Yang ${ }^{2,3^{*}}$ \\ ${ }^{1}$ KNOTUS Co., Ltd. Research Center, Guri-Si, Gyeonggi-Do, Republic of Korea. \\ ${ }^{2}$ Chonbuk National University, College of Veterinary Medicine, Department of Veterinary Medicine, Biosafety Research Institute, Iksan, Jeonbuk, \\ Republic of Korea. \\ ${ }^{3}$ Chonbuk National University, Department of Veterinary Pharmacology and Toxicology, Iksan Campus, Jeollabuk-do, Republic of Korea.
}

\begin{abstract}
The objective of our study was to evaluate the effects of pineapple (Ananas comosus) leaf powder (PLP) on broiler performance. One hundred male broiler chicks (aged one day) were divided into five groups consisting of four pens as replicates, which were treated with basal diet (normal control); basal diet supplemented with 1, 2, and 3\% PLP; or $50 \mathrm{mg} / \mathrm{kg}$ of zinc bacitracin $(\mathrm{ZnB})$ as a positive control for 35 days. Body weights were significantly increased by $1.06,5.67,13.15$, and $11.92 \%$, respectively, and feed conversion ratios were decreased by $2.36,8.49,12.06$, and $11.43 \%$, respectively, in $1,2,3 \%$ PLP- and ZnB-supplemented groups, compared with the normal control group. Notably, the 2 and 3\% PLP supplementations had beneficial effects on broiler performance, similar to that of the positive group. Haematological parameters, such as red blood count, haemoglobin, and haematocrit, were improved in the 3\% PLP-supplemented group, but no significant differences in white blood count and its differential count were observed. The serum biochemical parameters, such as creatinine and blood urea nitrogen, were found to be decreased in the 2 and 3\% PLP-supplemented groups, compared with the normal control group. Finally, 2 and 3\% PLP supplementations dramatically decreased the caecal coliform and Escherichia coli populations, but increased the lactobacillus population. Taken together, our results suggest that PLP improves the performance of broilers and balances the gut microbial population. Therefore, PLP can be used as a supplement in the diet of broilers.
\end{abstract}

Key Words: Ananas comosus leaf, broiler performance, caecal microbial population, PLP supplementation

\section{Introduction}

The use of antibiotics as growth-promoting substances in poultry industry is risky because of the development of cross-resistance among pathogens and the harm they cause to humans once they enter the food cycle (Marshall and Levy, 2011). Their use as growth promoters is prohibited in many countries (Attia et al, 2011). Alternative growth promoters from herbal plants and their bioactives are becoming more important because of their antimicrobial effects and digestion-enhancing capacities (Dhama et al., 2015; Attia et al., 2017a; Attia et al., 2017b).

Pineapple (Ananas comosus), from the Bromeliaceae family, is an important fruit worldwide. It grows extensively in countries like the Philippines, Hawaii,

Received: March 6, 2017

Accepted: January 11, 2018

*Corresponding author: dkyang0502@gmail.com

Copyright (C) 2018 Sociedade Brasileira de Zootecnia. This is an Open Access article distributed under the terms of the Creative Commons Attribution License (http://creativecommons.org/licenses/by/4.0/), which permits unrestricted use, distribution, and reproduction in any medium, provided the original work is properly cited.
Thailand, Malaysia, Brazil, China, India, Bangladesh, the Caribbean area, Australia, Mexico, and South Africa (Xie et al., 2007; Hu et al., 2011; BBS, 2013). The annual mean world production was reported to be over 13 million metric tons in recent years (Hu et al., 2011). High production and worldwide distribution denotes the importance of utilization and management of its byproducts. Pineapple waste residues can be converted into commercial value-added products and are used as substrates for the production of methane, ethanol, citric acid, and antioxidant compounds (Ketnawa et al., 2011; Domingues et al., 2013). Pineapple fruits and different plant parts are considered to have numerous traditional medicinal values. Pineapple leaves have many applications in folk medicines; they are anti-diabetic, antidyslipidemic, antioxidant, antidyspeptic, antidiarrheal, anti-inflammatory, antimicrobial, and antihelmintic (Xie et al., 2007; Hu et al., 2011; Dutta and Bhattacharyya, 2013). Pineapple and pineapple leaves contain various phytogenic compounds with pharmacological properties, including phenolics, flavonoids, and antioxidants. Among these, active ingredients exhibiting pharmacological activities, such as bromelain (Ketnawa et al., 2011; Dutta and Bhattacharyya, 2013), gallic 
acid (Sen et al., 2013), vianain (Kane and Goldberg, 2000), 1-O-caffeoylglycerol, 1,3-O-dicaffeoylglycerol, caffeic acid, 1-O-p-coumaroylglycerol, and p-coumaric acid (Xie et al., 2007; Hu et al., 2011), and cysteine protease (Stepek et al., 2006) have been identified. Herein, we investigated the effects of pineapple leaf powder (PLP) on growth and haematological and biochemical parameters of broilers and compared these effects with those of growth promotor zinc bacitracin $(\mathrm{ZnB})$, widely used to improve the performance of food animals.

\section{Material and Methods}

For the preparation of powder, pineapple leaves were cleaned, sliced into small pieces, dried in the sun for 10 days, and then placed in an oven at $55-60{ }^{\circ} \mathrm{C}$ for $24 \mathrm{~h}$. The dried leaves were pulverized with a blender and ground to powder form ( 0.25 to $0.5 \mathrm{~mm}$ particle size to ensure homogeneity); the powder was preserved in an airtight plastic container until it was directly used for feeding. Pineapple leaf powder was mixed properly with feed at 1 , 2 , and $3 \%$.

All the animal experiments in this study were approved by the local Animal Care Committee (case no. CBNU2016-67) and were performed according to the local guidelines.

One hundred Cobb 500 broiler chickens aged one day were randomly divided into five groups (normal control, $1 \%$ PLP, 2\% PLP, 3\% PLP, and positive control with $50 \mathrm{mg} / \mathrm{kg} \mathrm{ZnB}$ [Tianjin (Mainland), Qingdao, Shanghai] treated groups) with four pens as replicates of five chicks each. Environmentally controlled room and wire-floored cages system were used for housing. The lighting regiment and ventilation were continuously monitored. Birds had access to feed and water ad libitum. During the experimental period, relative humidity was $44.66 \%$. The room temperature was maintained at $35^{\circ} \mathrm{C}$ for the first three days gradually reduced thereafter to $32{ }^{\circ} \mathrm{C}$, and maintained there for 35 days. Standard biosecurity was strictly maintained, and vaccinations were applied. Handmade formulated diet was supplied to meet broiler nutrient requirements (Rahman et al., 2016) for starter (1-21 days) and finisher (22-35 days) growth periods (Table 1). The birds were carefully monitored to observe any toxicity by recording clinical signs and mortality three-five times daily. Body weight (BW) was measured once a week. Feed intake was calculated by measuring the weight of the supplied feed and the remaining feed in each pen. Bird weight was measured weekly. Weight gain was measured from the difference between the initial weight and the final weight.
Feed conversion ratio (FCR) was calculated as follows: $\mathrm{FCR}=$ total feed intake/weight gain.

At the end of the experimental period (week 5), birds were deprived of food for $6 \mathrm{~h}$. Ten they were randomly selected per treatment group, and $4 \mathrm{~mL}$ blood was collected from the jugular vein. Slaughter was performed manually with sharpened knives, and birds were eviscerated manually for determination of carcass yield. Knives were manually sharpened at the beginning and were washed before each bird was slaughtered and eviscerated.

Haematological parameters were measured by MHX-2 haematology analyser (MH Medical Co., Ltd., Jilin, China), and serum biochemical parameters were determined by Hitachi 2178 chemistry analyser (Hitachi, Tokyo, Japan).

After slaughter, the caecal contents of each bird were collected and pooled. Microbial populations were determined by serial dilution $\left(10^{-4}\right.$ to $\left.10^{-6}\right)$ of caecal samples in anaerobic diluents and then inoculated onto Petri dishes containing sterile agar, as previously described (Bryant and Burkey, 1953). The results were expressed as colony forming unit $\log 10$ per gram of fresh sample. There were Escherichia coli on eosin methylene blue agar, coliforms on MacConkey agar (EMD Millipore, MA, USA), and lactobacilli on LMRS agar (Difco Laboratories, Madrid, Spain) plates. Inoculation, incubation, and counting time were performed according to the manufacturers' protocols. Distinct colonies were used to define the colony forming units and the colony diameter was at least $1 \mathrm{~mm}$.

Data were analysed using analysis of variance (ANOVA) with Student's t test or by two-way ANOVA

Table 1 - Composition of experimental diets

\begin{tabular}{|c|c|c|}
\hline & $\begin{array}{c}\text { Starter } \\
\text { (1 to } 21 \text { days) }\end{array}$ & $\begin{array}{c}\text { Finisher } \\
\text { (22 to } 35 \text { days) }\end{array}$ \\
\hline Corn & 59.66 & 63.55 \\
\hline Soybean meal & 27.02 & 30.11 \\
\hline Wheat bran & 10.00 & 3.50 \\
\hline Dicalcium phosphate & 1.19 & 1.12 \\
\hline Limestone & 1.40 & 1.07 \\
\hline Salt & 0.40 & 0.40 \\
\hline DL-methionine & 0.13 & 0.05 \\
\hline Vitamin premix ${ }^{1}$ & 0.10 & 0.10 \\
\hline Mineral premix ${ }^{2}$ & 0.10 & 0.10 \\
\hline Total calculated values & 100 & 100 \\
\hline Metabolisable energy (kcal/kg) & 3,100 & 3,100 \\
\hline Crude protein $(\%)$ & 21.50 & 19.00 \\
\hline Methionine (\%) & 0.50 & 0.38 \\
\hline Lysine (\%) & 1.10 & 1.00 \\
\hline Calcium (\%) & 1.00 & 0.90 \\
\hline Available phosphorous (\%) & 0.45 & 0.35 \\
\hline \multicolumn{3}{|c|}{$\begin{array}{l}1 \text { Vitamin premix provides the following (per kg of diet): vitamin } \mathrm{A}, 5500 \mathrm{IU} \\
\text { vitamin D3, } 1100 \mathrm{IU} \text {; vitamin E, } 10 \mathrm{IU} \text {; riboflavin, } 4.4 \mathrm{mg} \text {; vitamin B12, } 12 \mathrm{mg} \\
\text { nicotinic acid, } 44 \mathrm{mg} \text {; menadione, } 1.1 \mathrm{mg} \text {; biotin, } 0.11 \mathrm{mg} \text {; thiamine, } 2.2 \mathrm{mg} \text {; and } \\
\text { ethoxyquin, } 125 \mathrm{mg} \text {. } \\
{ }^{2} \text { Mineral premix provides the following (per kg of diet): Mn, } 120 \mathrm{mg} \text {; } \mathrm{Zn}, 100 \mathrm{mg} \\
\mathrm{Fe}, 60 \mathrm{mg} \text {; } \mathrm{Cu}, 10 \mathrm{mg} \text {; Se, } 0.17 \mathrm{mg} \text {; } 10.46 \mathrm{mg} \text {; Ca, minimum: } 150 \mathrm{mg} \text {, maximum } \\
180 \mathrm{mg} \text {. }\end{array}$} \\
\hline
\end{tabular}


with the Bonferroni post-hoc test versus the normal control group ( $\mathrm{n}=20$ per group), using Prism 5.03 (GraphPad Software Inc., San Diego, CA, USA). All data from each pen were considered the experimental unit for growth performance (four replicates in each group). All the results were expressed as mean \pm SEM and were considered statistically significant when $\mathrm{P}<0.05$.

\section{Results}

On the 28th day, there was a significant increase in BW $(\mathrm{P}<0.05)$ in the $3 \%$ PLP-treated group (Figure 1). At the end of the day (on the 35th day), final BW and weight gain were significantly increased $(\mathrm{P}<0.05)$ (Figure 1 and Table 2), but feed intake $(\mathrm{P}<0.05)$ (Table 2) and FCR (Table 2 ) were markedly decreased $(\mathrm{P}<0.05)$ in 2 and $3 \%$ PLP-treated groups compared with the control group. It was also found that $1 \%$ PLP supplementation tended to change broiler performance, such as weight gain, feed intake, and FCR, with similar patterns of those in 2 and 3\% PLP-treated groups, although the changes were not significant compared with the control group (Table 2).

There were no significant differences in the haematological parameters, such as WBC, lymphocyte, monocyte, and basophil and eosinophil counts in all the PLP-treated groups compared with the control group (Table 3). In addition, PLP supplementation improved serum biochemical parameters, such as aspartate aminotransferase (AST), alanine aminotransferase (ALT), blood urea nitrogen (BUN), and creatine (CRE) compared with the control group (Table 4).

The coliforms and E. coli bacterial populations were significantly decreased $(\mathrm{P}<0.05)$ in all the PLPtreated groups compared with those in the control group. Conversely, the lactobacillus bacterial population was significantly increased $(\mathrm{P}<0.001)$ by 2 and $3 \%$ PLP supplementations compared with that of the control group (Figure 2).

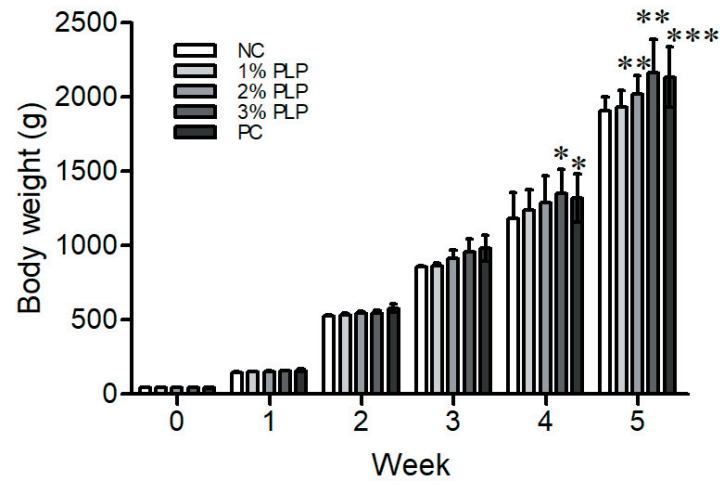

NC - normal control; $1 \%$ PLP - 1\% pineapple leaf powder-treated group; $2 \%$ PLP - $2 \%$ pineapple leaf powder-treated group; 3\% PLP - 3\% pineapple leaf powder-treated group; PC - positive control with $50 \mathrm{mg} / \mathrm{kg}$ Zinc Bacitracin treatment.

Data are reported as mean \pm SEM which represents four replicates with five chicks per replicate.

$* \mathrm{P}<0.05, * * \mathrm{P}<0.01$, and $* * * \mathrm{P}<0.001$, Bonferroni post hoc test following two-way ANOVA versus the normal control group.

Figure 1 - Effects of dietary pineaple leaf powder supplementation on body weight of broiler chicken from 0-35 days.

Table 2 - Effects of dietary pineaple leaf powder supplementation on broiler performance

\begin{tabular}{|c|c|c|c|c|c|}
\hline & $\mathrm{NC}$ & $1 \%$ PLP & $2 \%$ PLP & $3 \%$ PLP & $\mathrm{PC}$ \\
\hline Initial BW (at 1 day; g) & $43.1 \pm 1.2$ & $42.4 \pm 1.1$ & $43.5 \pm 1.2$ & $44.0 \pm 1.2$ & $43.8 \pm 1.2$ \\
\hline Final BW (at 35 days; g) & $1909.8 \pm 28.9$ & $1930.1 \pm 36.8$ & $2018.0 \pm 39.4^{*}$ & $2160.9 \pm 71.8 * *$ & $2132.9 \pm 64.2 * *$ \\
\hline Weight gain ( 1 to 35 days; g) & $1866.6 \pm 32.2$ & $1887.7 \pm 37.0$ & $1974.5 \pm 39.7 *$ & $2116.9 \pm 72.9 * *$ & $2089.1 \pm 64.6 * *$ \\
\hline Feed intake ( 1 to 35 days; $g$ ) & $3197.4 \pm 61.1$ & $3156.6 \pm 46.4$ & $3094.0 \pm 18.7^{*}$ & $3158.8 \pm 66.8$ & $3149.8 \pm 47.4$ \\
\hline
\end{tabular}

BW - body weight; NC - normal control; PLP - pineapple leaf powder-treated group; PC - positive control with $50 \mathrm{mg} / \mathrm{kg}$ Zinc Bacitracin treatment.

Data are reported as the mean \pm standard error of the mean, which represents four replicates with five chicks per replicate.

$* \mathrm{P}<0.05$ and $* * \mathrm{P}<0.01$; Student's t-test versus control group.

Table 3 - Effects of dietary pineaple leaf powder supplementation on haematological parameters of chickens after 35 days

\begin{tabular}{|c|c|c|c|c|c|}
\hline Parameter & $\mathrm{NC}$ & $1 \%$ PLP & $2 \%$ PLP & $3 \%$ PLP & $\mathrm{PC}$ \\
\hline Red blood count $\left(\times 10^{6} / \mu \mathrm{L}\right)$ & $2.71 \pm 0.02$ & $2.71 \pm 0.02$ & $2.76 \pm 0.01$ & $2.78 \pm 0.02 *$ & $2.71 \pm 0.04$ \\
\hline Haemoglobin $(\mathrm{g} / \mathrm{dL})$ & $9.86 \pm 0.03$ & $9.87 \pm 0.02$ & $9.93 \pm 0.02$ & $10.00 \pm 0.03 * *$ & $9.90 \pm 0.09$ \\
\hline Haematocrit $(\%)$ & $33.30 \pm 0.54$ & $33.80 \pm 0.29$ & $34.70 \pm 0.33$ & $35.10 \pm 0.31 * *$ & $34.70 \pm 0.30^{*}$ \\
\hline Lymphocyte (\%) & $69.78 \pm 0.37$ & $69.78 \pm 0.43$ & $70.78 \pm 0.35$ & $69.78 \pm 0.33$ & $70.45 \pm 0.60$ \\
\hline Monocyte (\%) & $4.22 \pm 0.04$ & $4.26 \pm 0.04$ & $4.20 \pm 0.06$ & $4.18 \pm 0.05$ & $4.30 \pm 0.10$ \\
\hline Basophil (\%) & $24.55 \pm 0.16$ & $24.42 \pm 0.23$ & $24.31 \pm 0.21$ & $24.34 \pm 0.17$ & $24.38 \pm 0.16$ \\
\hline
\end{tabular}

$\mathrm{NC}$ - normal control; PLP - pineapple leaf powder-treated group; PC - positive control with $50 \mathrm{mg} / \mathrm{kg}$ Zinc Bacitracin treatment.

Data are reported as the mean \pm standard error of the mean, which represents four replicates with five chicks per replicate.

$* \mathrm{P}<0.05, * * \mathrm{P}<0.01$, and $* * * \mathrm{P}<0.001$; Student's t-test versus control group. 
Table 4 - Effects of dietary pineaple leaf powder supplementation on serum biochemical parameters of chicken after 35 days

\begin{tabular}{|c|c|c|c|c|c|}
\hline$\underline{\text { Parameter }}$ & $\mathrm{NC}$ & $1 \%$ PLP & $2 \%$ PLP & $3 \%$ PLP & $\mathrm{PC}$ \\
\hline AST (IU/L) & $251 \pm 8$ & $250 \pm 7$ & $246 \pm 5$ & $229 \pm 7 *$ & $239 \pm 4$ \\
\hline ALT (IU/L) & $21 \pm 3$ & $20 \pm 2$ & $19 \pm 1$ & $17 \pm 2 *$ & $20 \pm 2$ \\
\hline BUN (mg/dL) & $6.31 \pm 0.06$ & $6.25 \pm 0.04$ & $6.17 \pm 0.02 *$ & $6.01 \pm 0.11^{*}$ & $6.24 \pm 0.04$ \\
\hline $\mathrm{UA}(\mathrm{mg} / \mathrm{dL})$ & $4.47 \pm 0.05$ & $4.45 \pm 0.05$ & $4.31 \pm 0.03 *$ & $4.32 \pm 0.04$ & $4.26 \pm 0.04$ \\
\hline $\mathrm{TP}(\mathrm{mg} / \mathrm{dL})$ & $5.09 \pm 0.14$ & $5.15 \pm 0.21$ & $5.17 \pm 0.21$ & $5.17 \pm 0.21$ & $5.14 \pm 0.21$ \\
\hline $\operatorname{ALB}(\mathrm{mg} / \mathrm{dL})$ & $3.31 \pm 0.06$ & $3.31 \pm 0.05$ & $3.34 \pm 0.06$ & $3.33 \pm 0.04$ & $3.31 \pm 0.04$ \\
\hline
\end{tabular}

AST - aspartate aminotransferase; ALT - alanine aminotransferase; CRE - creatinine; BUN - blood urea nitrogen; UA - uric acid; TP - total protein; ALB - albumin; NC - normal control; PLP - pineapple leaf powder treated group; PC - positive control with $50 \mathrm{mg} / \mathrm{kg}$ Zinc Bacitracin treatment.

Data are reported as the mean \pm standard error of the mean, which represents four replicates with five chicks per replicate.

$* \mathrm{P}<0.05$ and $* * \mathrm{P}<0.01$; Student's t test versus control group.
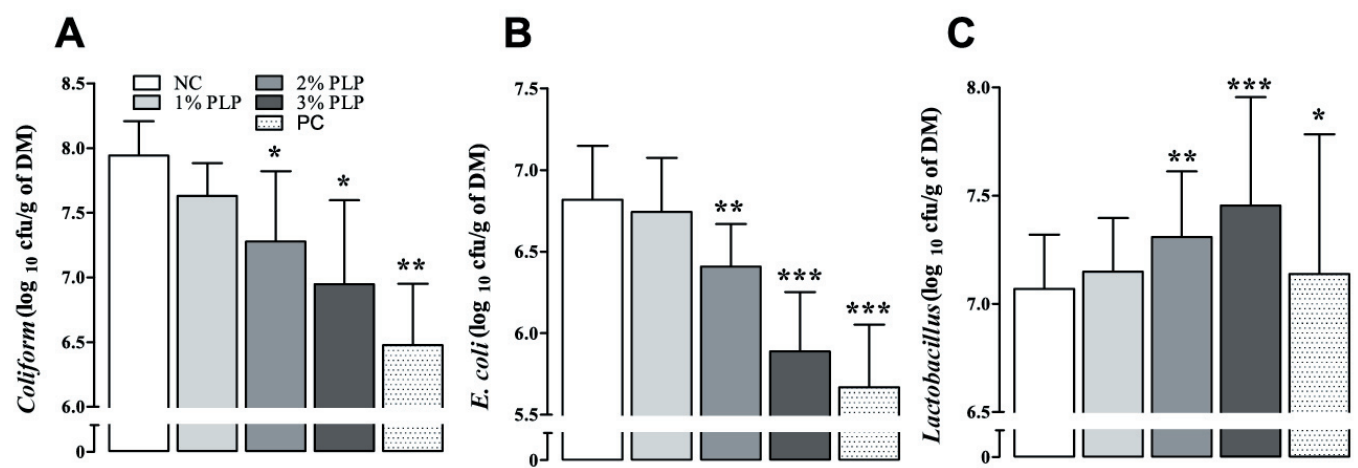

NC - normal control; $1 \%$ PLP - 1\% pineapple leaf powder-treated group; $2 \%$ PLP - 2\% pineapple leaf powder-treated group; $3 \%$ PLP - 3\% pineapple leaf powder-treated group; $\mathrm{PC}$ - positive control with $50 \mathrm{mg} / \mathrm{kg}$ Zinc Bacitracin treatment.

Data are reported as mean \pm SEM which represents four replicates with five chicks per replicate.

$* \mathrm{P}<0.05, * * \mathrm{P}<0.01$, and *** $\mathrm{P}<0.001$; Student's t test versus control group.

Figure 2 - Effects of dietary pineapple leaf powder supplementation on caecal microbial populations of chicken after 35 days.

\section{Discussion}

No clinical signs or mortality and even and regular increase in body weight in all broilers during the experiment prove that PLP is not toxic for broilers (Figure 1). Pineapple and pineapple leaves also have high nutritive value and are rich sources of vitamins $\mathrm{A}, \mathrm{B}$, and $\mathrm{C}$ and several minerals (e.g. calcium, phosphorus, and iron) (Hossain et al., 2011). In this study, we demonstrated that by 2 and 3\% PLP supplementation, broiler performance was significantly increased compared with the control group (Table 2). Therefore, we conclude that these improvements in the broiler performance by PLP supplementation might also be due to the nutritional benefits of pineapple leaves.

We also confirmed the non-toxicity of PLP from our haematological and serum biochemical parameters, which were not changed after PLP supplementation. Indeed, a previous study demonstrated that exposure to toxic substances increases the blood-related parameters (Rahman et al., 2015). In addition, another study also showed that the PLP treatment improved the red blood count, haemoglobin, and haematocrit values within the normal ranges (Mitruka and Rawnsley, 1981). We also found that serum biochemical parameters, such as AST, ALT, CRE, and BUN, improved in the PLP-treated groups (Table 4). Thus, the present results indicate that pineapple leaves have nutritional benefits in broilers.

Among the chemical compounds in pineapple and pineapple leaves, bromelain is a protease enzyme like trypsin or pepsin, which is active in the gut and enhances digestion by breaking down proteins. It improves the intestinal permeability and reduces the side effects associated with antibiotics such as penicillin and tetracycline after oral administration (Neubauer, 1961; Maurer, 2001). Bromelain also improves some symptoms of ulcerative colitis in people who have persistent disease despite on-going standard therapy (Kane and Goldberg, 2000). In addition, gallic acid possesses anti-ulcer effects, which causes significantly decreased ulcer index, gastric juice volume, and free and total acidity in ulcer rat model (Sen et al., 2013). A previous study also showed that pineapple facilitates digestion and accelerates wound healing (Maurer, 2001). In this regard, we demonstrated that PLP supplementations might improve intestinal 
functional activities and enhance digestion, leading to a better feed utilization and assimilation and, consequently, decreased feed conversion ratio and improved body weight (Figure 2).

In this study, our results showed that the populations of coliforms and E. coli were significantly decreased and that of lactobacillus was significantly increased by 2 and $3 \%$ PLP supplementations compared with the control group (Figure 2). Pineapple and pineapple waste products act as growth media for the probiotic, lactobacillus bacteria (Di Cagno et al., 2010; Hassan et al., 2014; Russoet al., 2014). Furthermore, it also has a protective effect against pathogenic bacteria like E. coli and Listeria monocytogenes (Russo et al., 2014). Indeed, several studies have demonstrated that the pineapple leaf or its ingredients have a wide range of antibacterial, antiprotozoal, and anthelmintic actions (Stepek et al., 2006; Domingues et al., 2013; Ali et al., 2015;). We suggest that the body weight gain of broilers upon PLP supplementation may also be due to the antimicrobial and anti-parasitic properties of PLP, which help to impair adhesion of pathogens and to stabilize microbial balance in the gut, leading to better feed utilisation and assimilation, and thereby, improving the feed intake and feed efficiency of the birds.

\section{Conclusions}

We propose that pineapple leaf powder supplementation improves broiler performance, decreases feed conversion ratio, and balances gut microbial population. Moreover, our results for the haematological and serum biochemical parameters indicate that this supplementation has no deleterious effects. Therefore, it could be considered as a feed addictive in the broiler industry.

\section{References}

Ali, A. A.; Milala, M. A. and Gulani, I. A. 2015. Antimicrobial effects of crude bromelain extracted from pineapple fruit (Ananas comosus (Linn.) Merr.). Advances in Biochemistry 3:1-4.

Attia, Y. A.; Zeweil, H. S.; Alsaffar, A. A. and El-Shafy, A. S. 2011. Effect of non-antibiotic feed additives as an alternative to flavomycin on broiler chickens production. Archiv für Geflügelkunde 75:S40-48.

Attia, Y. A.; Bakhashwain, A. A. and Bertu, N. K. 2017a. Thyme oil (Thyme vulgaris L.) as a natural growth promoter for broiler chickens reared under hot climate. Italian Journal of Animal Science 16:275-282.

Attia, Y. A.; Al-Harthi, M. A. and Hassan, S. S. 2017b. Turmeric (Curcuma longa Linn.) as a phytogenic growth promoter alternative for antibiotic and comparable to mannan oligosaccharides for broiler chicks. Revista Mexicana de Ciencias Pecuarias 8:11-21.
BBS - Bangladesh Bureau of Statistics. 2013. Statistics and Informatics Division (SID) Ministry of Planning. Report on the productivity survey of pineapple crop.

Bryant, M. P. and Burkey, L. A. 1953. Cultural methods and some characteristics of some of the more numerous groups of bacteria in the bovine rumen. Journal of Dairy Science 36:205-217.

Dhama, K.; Latheef, S. K.; Mani, S.; Samad, H. A; Karthik, K; Tiwari, R; Khan, R. U.; Alagawany. M; Farag, M. R; Alam, G. M.; Laudadio, V. and Tufarelli, V. 2015. Multiple beneficial applications and modes of action of herbs in poultry health and production - A review. International Journal of Pharmacology 11:152-176.

Di Cagno, R.; Cardinali, G.; Minervini,G.; Antonielli, L.; Rizzello, C. G.; Ricciuti, P. and Gobbetti, M. 2010. Taxonomic structure of the yeasts and lactic acid bacteria microbiota of pineapple (Ananas comosus L. Merr.) and use of autochthonous starters for minimally processing. Food Microbiology 27:381-389.

Domingues, L. F.; Giglioti, R.; Feitosa, K. A.; Fantatto, R. R.; Rabelo, M. D.; Sena Oliveira, M. C.; Bechara, G. H.; Oliveira, G. P.; Barioni Junior, W. and de Souza Chagas, A. C. 2013. In vitro and in vivo evaluation of the activity of pineapple (Ananas comosus) on Haemonchus contortus in Santa Ines sheep. Veterinary Parasitology 197:263-270.

Dutta, S. and Bhattacharyya, D. 2013. Enzymatic, antimicrobial and toxicity studies of the aqueous extract of Ananas comosus (pineapple) crown leaf. Journal of Ethnopharmacology 150:451-457.

Hassan, P.; Liong, M. T. and Peh, K. K. 2014. Potentials of pineapple waste as growth medium for lactobacillus species. International Journal of Pharmacy \& Pharmaceutical Sciences 6:142-145.

Hossain, M. A. and Rahman, S. M. 2011. Total phenolics, flavonoids and antioxidant activity of tropical fruit pineapple. Food Research International 44:672-676.

Hu, J.; Lin, H.; Shen, J.; Lan, J.; Ma, C.; Zhao, Y.; Lei, F.; Xing, D. and Du, L. 2011. Developmental toxicity of orally administered pineapple leaf extract in rats. Food and Chemical Toxicology 49:1455-1463.

Kane, S. and Goldberg, M. J. 2000. Use of bromelain for mild ulcerative colitis. Annals of Internal Medicine 132:680.

Ketnawa, S.; Chaiwut, P. and Rawdkuen, S. 2011. Extraction of bromelain from pineapple peels. Food Science and Technology International 17:395-402.

Marshall, B. M. and Levy, S. B. 2011. Food animals and antimicrobials: impacts on human health. Clinical Microbiology Reviews 24:718-733.

Maurer, H. R. 2001. Bromelain: biochemistry, pharmacology and medical use. Cellular \& Molecular Life Sciences 58:1234-1245.

Mitruka, B. M. and Rawnsley, H. M. 1981. Clinical biochemical and hematological reference values in normal experimental animals and normal humans. Masson Publ., New York, USA.

Neubauer, R. A. 1961. A plant protease for potentiation of and possible replacement of antibiotics. Experimental Medicine and Surgery 19:143-160.

Rahman, M. M. and Kim, S. J. 2016. Efects of dietary Nigella sativa seed supplementation on broiler productive performance, oxidative status and qualitative characteristics of thighs meat. Italian Journal of Animal Science 15:241-247.

Rahman, M. M.; Lee, S. J.; Kim, G. B.; Yang, D. K.; Alam, M. R. and Kim, S. J. 2015. An accidental fatal attack on domestic pigeons by honey bees in Bangladesh. The Journal of Veterinary Medical Science 77:1489-1493.

Russo, P.; de Chiara, M. L. V.; Vernile, A.; Amodio, M. L.; Arena, M. P.; Capozzi, V.; Massa, S. and Spano, G. 2014. Fresh-cut pineapple as a new carrier of probioticlactic acid bacteria. BioMed Research International 2014:309183. https://doi.org/10.1155/2014/309183 
Sen, S.; Asokkumar, K.; Umamaheswari, M.; Sivashanmugam, A. T. and Subhadradevi, V. 2013. Antiulcerogenic effect of gallic acid in rats and its effect on oxidant and antioxidant parameters in stomach tissue. Indian Journal of Pharmceuticals Science 75:149-155.

Stepek, G.; Lowe. A. E.; Buttle, D. J.; Duce, I. R. and Behnke, J. M. 2006. In vitro and in vivo anthelmintic efficacy of plant cysteine proteinases against the rodent gastrointestinal nematode, Trichuris muris. Parasitology 132(P5):681-689.

Xie, W.; Wang, W.; Su, H.; Xing, D.; Cai, G. and Du, L. 2007. Hypolipidemic mechanisms of Ananas comosus L. leaves in mice: different from fibrates but similar to statins. Journal of Pharmacological Sciences 103:267-274. 